\title{
Characterisation of the Physical and Metallurgical Properties of Natural Iron Ore for Iron Production
}

\author{
Abraham J. B. Muwanguzi, ${ }^{1,2}$ Andrey V. Karasev, ${ }^{1}$ \\ Joseph K. Byaruhanga, ${ }^{2}$ and Pär G. Jönsson ${ }^{1}$ \\ ${ }^{1}$ Department of Material Science and Engineering, KTH Royal Institute of Technology, Brinellvägen 23, 10044 Stockholm, Sweden \\ ${ }^{2}$ Department of Mechanical Engineering, School of Engineering, College of Engineering Design Art and Technology, \\ Makerere University, P.O. Box 7062, Kampala, Uganda
}

Correspondence should be addressed to Abraham J. B. Muwanguzi, ajbm@kth.se

Received 26 April 2012; Accepted 10 June 2012

Academic Editors: C. Ribeiro and J. Rubio

Copyright (C) 2012 Abraham J. B. Muwanguzi et al. This is an open access article distributed under the Creative Commons Attribution License, which permits unrestricted use, distribution, and reproduction in any medium, provided the original work is properly cited.

\begin{abstract}
The blast furnace is still the dominant form of iron production, but over the years, direct reduction methods have increased due to a number of reasons. Overall, iron production methods have optimal requirements with respect to the feed materials especially iron ore. In this study, tests were carried out on Muko iron ore from Uganda to analyse its suitability to meet the feed requirements of today's dominant iron production methods. More specifically, the Tumbler, Abrasion, and Shatter Indices of the ore were determined. In addition, porosity, thermoanalysis, and reducibility tests were performed. Overall, the Muko ore was found to have good mechanical properties exemplified with tumble and shatter index data $>89.0 \mathrm{wt} \%$ and $<2.5 \mathrm{wt} \%$, respectively. Furthermore, its reducibility at $0.87 \% / \mathrm{min}$ is within the acceptable range as a natural material feed for blast furnace and direct reduction furnaces. Also, the energy requirement for heating the ore to $1100^{\circ} \mathrm{C}$ was found to be higher in the samples containing a wider size range of irregular grains and the largest contaminations. In summary, it is concluded that the Muko iron ore has good physical and metallurgical properties to serve as a natural material for the blast furnace and direct reduction furnaces.
\end{abstract}

\section{Introduction}

Iron, along with its generic products, is currently the most widely utilised metal in the various sectors of the world's economy. Many factors contribute to this, ranging from the good mechanical properties it possesses to the low cost associated with its production. Iron is mainly produced through two methods; the blast furnace, $\mathrm{BF}$, route (pig iron), and the direct reduction, DR, route (sponge iron). According to the World Steel Association, 2011 [1], crude steel production was standing at 1.4 billion tonnes by the end of 2010. Of these, $70 \%$ was produced via the basic oxygen furnace (BOF), which uses pig iron from the blast furnace, and $28 \%$ via the electric arc furnace (EAF), which uses sponge iron and scrap [1].

Iron ore can be used directly in its natural form as a raw material for processing iron or it can be upgraded through beneficiation before it's charged into the BF or DR furnaces.
The feedstock is evaluated for physical and metallurgical properties [2]. Physical properties give an indication of the material behaviour during handling and descent in the furnace. Metallurgical properties on the other hand indicate the materials' behaviour during the reduction process. In selecting iron ore for iron and steel industries, some of the properties which need to be considered include (i) tumbler, abrasion and shatter indices, (ii) porosity, (iii) chemical composition, (iv) loss on ignition, (v) reduction behavior, and (vi) thermal degradation [3].

The performance of a blast furnace depends to a great extent on the physical and chemical characteristics of the materials. The burden materials, which are charged through the throat, are coke, lump ores, and agglomerated ores in the form of sinter or pellets. Lump ores are significantly cheaper than pellets and sinters. However, they are inferior, particularly with respect to softening-melting and they affect the smooth running of the blast furnace and increase the 
coke consumption [4]. Swelling and disintegration of iron ore have been two major draw backs in their acceptance as feed for blast furnaces and direct reduction furnaces [5]. Therefore, natural iron ore as mined from the earth has been almost completely replaced as a feed for iron blast furnaces by sinters and pellets.

In the study of natural ores, [6], it was found that the chemical composition and microstructure of natural iron from Muko deposits in Uganda corresponds to the demands on high grade iron ore. Precisely, the Fe, silica, and alumina contents indicate that they can profitably be used for iron production. The current study examines the physical and metallurgical properties of Muko iron ore, from Uganda. It evaluates these with respect to the requirements for the different iron production methods/processes, in order to establish the ore's suitability in meeting the necessary demands for iron production. The iron ore samples are designated as Ug1-Rushekye, Ug2-Kamena, Ug3Kyanyamuzinda, Ug4-Nyamiyaga, Ug5-Butare, and Ug6Kashenyi. The first part of the paper presents the experimental procedure. Thereafter, the results are presented and discussed.

\section{Experimental}

2.1. Determination of Physical Properties. The physical properties of the ore were studied by determining their tumble, abrasion, and shatter indices as well as their apparent porosity.

A tumble strength test measures two mechanisms of feedstock degradation, that is, the Tumble Index (TI) and the Abrasion Index (AI). It was carried out following the International Standard ISO 3271:1995(E) for determination of Tumble Strength for iron ore [7]. Precisely, a $15 \mathrm{~kg}$ test block sample was tumbled in a circular drum rotating at $25 \mathrm{rpm}$ for 200 revolutions. Subsequently, the ore was screened and fractions $+6.3 \mathrm{~mm}$ and $-0.5 \mathrm{~mm}$ were obtained. The percentage of the fractions in proportion to the feed weight is the value of the $\mathrm{TI}(+6.3 \mathrm{~mm})$ and $\mathrm{AI}(-0.5 \mathrm{~mm})$. The test was repeated four times and the average values for these tests represent the final TI and AI data.

For estimation of a Shatter Index, a dried lump iron ore sample $(10 \mathrm{~kg})$ of size $-40+10 \mathrm{~mm}$ was dropped 4 times from a height of $2 \mathrm{~m}$ onto a cast iron floor $(0.5 \times 0.5 \times$ $0.03 \mathrm{~m}$ ). Thereafter, the iron ore was screened and the shatter index expressed as the wt $\%$ passing through a $5 \mathrm{~mm}$ sized screen (i.e., $-5 \mathrm{~mm}$ fraction). This procedure followed a test procedure suggested by [3], which were carried out on other ores.

The apparent porosity was determined using the GeoPyc 1360 pycnometer. A quantity of helium was placed in the sample chamber and its volume was measured. Thereafter, a $2.0 \mathrm{~g}$ iron ore piece was placed in the chamber together with the helium gas and the equipment registered the new volume values. The difference in the new and original helium volume gave the sample's envelope and skeletal volumes. The difference in the envelope and skeletal volumes indicates the percentage of porosity of the sample.
2.2. Determination of Metallurgical Properties. Thermoanalysis was performed using the Thermogravimetry-Differential Thermal Analysis-Mass Spectrometry (TGA and DTA) with a Netzsch STA 409 operated in an argon atmosphere. Heating was performed at a constant rate of $10^{\circ} \mathrm{C} / \mathrm{min}$, from $20^{\circ} \mathrm{C}$ up to $1450^{\circ} \mathrm{C}$. The temperature was held at $1450^{\circ} \mathrm{C}$ for 30 minutes and then ramped to $20^{\circ} \mathrm{C}$.

Reducibility was estimated following the procedure described by Chatterjee (1994) [8], using the Netzsch STA 409. The test employs isothermal reduction of the test portion, $500 \mathrm{~g}$, on a fixed bed at $950^{\circ} \mathrm{C}$ using reducing gases consisting of $40 \% \mathrm{CO}$ and $60 \% \mathrm{~N}_{2}$. During the test, the sample's weight reductions were recorded at specified intervals.

\section{Results and Discussion}

3.1. Physical Properties. Physical properties of iron ores are determined by using cold strength testing. Tests such as tumbler and shatter tests give an indication of the material behaviour during ore mining, loading, transportation, handling, and screening. They also give an insight into the material's behaviour, during an initial period of the reduction process in its descent in the furnace.

The obtained results of the physical properties for the natural iron ores from the different Muko ore deposits are given in Table 1. The limit values of the Tumble Index (TI) and Abrasion Index (AI) for the iron ore pellets used in furnace reduction process are $>70 \mathrm{wt} \%$ for the TI value and $<5 \mathrm{wt} \%$ for the AI value [2]. It follows from Table 1 that the TI values of Muko ores are between $88 \mathrm{wt} \%$ and $93 \mathrm{wt} \%$, which is significantly higher than the stipulated $70 \mathrm{wt} \%$. Therefore, the ores from all Muko deposits can be handled, loaded, and transported without disintegration to small particles. The AI values for Muko ores range from 0.54 to $3.41 \mathrm{wt} \%$, which is considerably lower than the acceptable abrasion limit $(<5 \mathrm{wt} \%)$. This implies that the amount of particles produced in form of dust during the subsequent handling processes after mining is within the acceptable range to enable an almost dust free handling environment.

During loading of the ore into the furnace, it is subjected to impact forces. Essentially, the requirement is that the ore must withstand impact forces as it descends down in the furnace. The reason is that small particles could clog the furnace bed and thereby block the rising reducing gas. The shatter test determines the ore's susceptibility to breakdown due to impact during loading, unloading and charging into the reduction furnace. With the Shatter Index value of Muko iron ore falling between $0.57 \mathrm{wt} \%$ and $2.01 \mathrm{wt} \%$, it can be noted that Muko ore can hold its form when subject to impact loading. As an example, the shatter index values of 10 commercial iron ore samples from ten different mines of Orissa in India were between $0.68 \mathrm{wt} \%$ to $1.80 \mathrm{wt} \%$ [3]. Comparison with these ores shows that Muko ores' Shatter Index value is within the same range as for these ores. Overall, it should be mentioned that the preferred Shatter Index value for iron ore for coal-based reduction is $<5 \mathrm{wt} \%$ and for the Midrex process is less than $10 \mathrm{wt} \%$ [11]. 
TABle 1: Physical properties of Muko iron ores.

\begin{tabular}{lcccc}
\hline Iron ore, deposit & $\begin{array}{c}\text { Tumble index } \\
(\mathrm{wt} \% \text { of }+6.3 \mathrm{~mm})\end{array}$ & $\begin{array}{c}\text { Abrasion index } \\
(\mathrm{wt} \% \text { of }-0.5 \mathrm{~mm})\end{array}$ & $\begin{array}{c}\text { Shatter index } \\
(\mathrm{wt} \% \text { of }-5.0 \mathrm{~mm})\end{array}$ & $\begin{array}{c}\text { Apparent porosity } \\
(\%)\end{array}$ \\
\hline Ug1, Rushekye & 89.72 & 0.83 & 1.17 & - \\
Ug2, Kamena & 88.45 & 1.50 & 1.21 & - \\
Ug3, Kyanyamuzinda & 91.68 & 0.54 & 0.57 & - \\
Ug4, Nyamiyaga & 90.39 & 0.88 & 1.31 & 14.3 \\
Ug5, Butare & 92.96 & 3.41 & 2.01 & 4.92 \\
Ug6, Kashenyi & 89.28 & 0.67 & 1.45 & - \\
\hline
\end{tabular}

Furthermore, for sinters for blast furnace iron reduction it is $<14-17$ wt $\%$ [9]. Thus, this comparison shows that the Muko iron ore meets the Shatter Index requirements for these iron production processes.

Muwanguzi et al. (2010) [6] showed that Muko ores (samples Ug1-6) have varying microstructures in terms of grain size, texture and inclusion distribution within the hematite matrix. The iron ore of Ug1 had a very fine granular structure (10 to $40 \mu \mathrm{m}$ ). Ug2 ore sample contained mostly hematite grains of sizes between 10 to $90 \mu \mathrm{m}$, which contained dark contaminations and had a fine crystalline platy structure. Furthermore, the Ug3 and Ug4 samples had almost a pure grey hematite matrix, which contained low amounts of small size dark contaminations (lower number of impurities). They also had a grey crystalline platy structure with some areas of fibrous texture. Also, the iron ores of the Ug5 and Ug6 samples contained the largest irregular grains ( $\sim 30$ to $350 \mu \mathrm{m}$ and $>500 \mu \mathrm{m})$ and layer-shaped dark contaminations within the structure. The values of TI and AI obtained in the current study do not show a clear correlation with the ore microstructure found in the previous study [6]. However, the Ug5 and Ug6 ore samples presented the highest values of the shatter index $(2.01 \mathrm{wt} \%$ and $1.45 \mathrm{wt} \%$, resp.). This may imply that the large grain structure, which contains larger contaminations, makes the ore more susceptible to breakage, when subject to impact loading.

Another important physical property of iron ore is its porosity. It facilitates access of reducing gas into the interior of the lump ore. A high porosity of materials promotes reducibility, as this provides a large interfacial area for a gas-solid contact. The porosity of lump iron ores for the DRI process is usually not limited, while the recommended value for the particle porosity for iron ore pellets is above $20 \%$ (HYL, 2010). In this study, the porosity values for the natural ore samples Ug5 and Ug6, which have larger amounts of gangue $\left(1.2 \% ; 5.1 \% \mathrm{SiO}_{2}\right.$ and $1.0 \% ; 6.0 \% \mathrm{Al}_{2} \mathrm{O}_{3}$, resp., Table 3 ) and microstructure with large size of hematite grains and impurity inclusions [6], were determined. The porosity value for the Ug6 sample, which had the lowest quality among the examined natural iron ores, was found to be $4.9 \%$. This is similar to the porosity values of the commercial lump iron ores used in the blast furnace (5.9\% for MBR Brazil iron ore) [15] and the direct reduction processes $(1.2-5.2 \%$ for Orissa India iron ores) [3]. Furthermore, sample Ug5, whose chemical composition is similar to that of samples Ug1-4 had a higher porosity value of $14.3 \%$.
Based on the obtained results, it can be stated that Muko iron ores have good physical properties, which enable proper handling and transportation with a good ability to withstand impact loading during the furnace charging process. The good mechanical strength of the natural iron ores may be attributed to its relatively low porosity and relatively uniform microstructure.

\subsection{Metallurgical Properties}

3.2.1. Thermoanalysis. A thermoanalysis test aids in understanding the behaviour of the different ores when subjected to raised temperatures, as it goes through the reduction process. The DTA analysis highlights the endothermal and exothermal effects and temperature ranges, which are correlated with the removal of physically present and structurally bonded water in the ore. It further highlights the occurrence of phase transformations. In addition, the weight of adsorbed water and structural $\mathrm{OH}$ can be determined by TGA analysis. The values of weight loss during heating of the different iron ore samples and the main characteristics of the endothermal (Peak 1) and exothermal (Peak 2) peaks are given in Table 2.

According to the obtained results, similar endothermal peaks of different values were observed between $365-632^{\circ} \mathrm{C}$ during heating of the ore samples Ug1-Ug5. Figure 1 shows the thermo-grams for samples Ug3 and Ug2. These had the biggest values (1076 J/g and $929 \mathrm{~J} / \mathrm{g}$, resp.) of the absorption energy (Peak 1). The Ug4 (745 J/g) and Ug5 (505 J/g) samples had medium peaks, as shown in Figure 2. The smallest peak (454 J/g) was detected in the sample Ug1 sample. In addition, the sample Ug6 exhibited a different behaviour pattern with no endothermal peak found in the studied temperature range in Figure 3.

Muwanguzi et al. (2010) [6] observed that all Muko ores mineralogically can predominantly be classed as hematite. Hematite occurs in two modifications: $\alpha$-hematite (crystal structure, hexagonal; much more prevalent) and $\gamma$-hematite (cubic lattice; forms only under special circumstances below $400-500^{\circ} \mathrm{C}$ ) [10]. Depending on its origin and the content of foreign ions, the maghemite ( $\gamma$-hematite), transforms to $\alpha$-hematite in the temperature range $370-600^{\circ} \mathrm{C}$ with a resulting endothermal effect. The endothermal peaks (Peak 1) observed in the Ug1-Ug5 samples are due to the transformation of maghemite to $\alpha$-hematite. In addition, the absence of the $\gamma-\alpha$ hematite phase transition in the Ug6 sample may be due to the larger content of chemically 


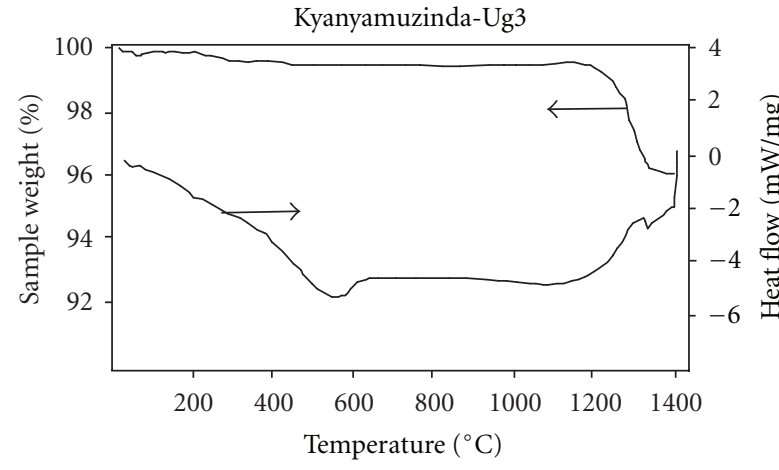

(a)

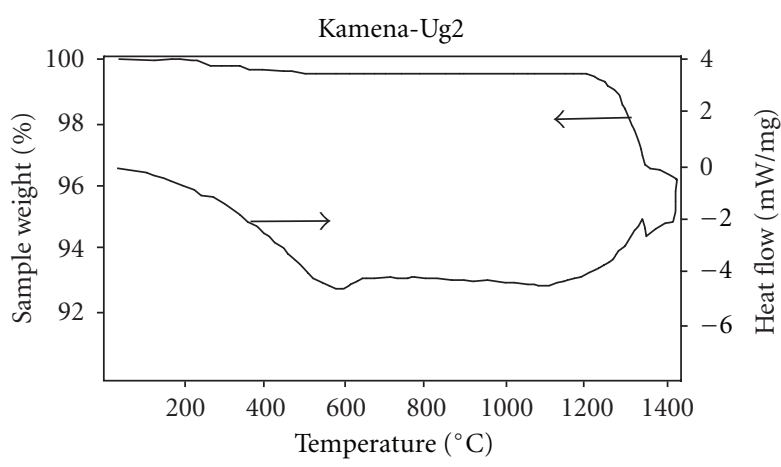

(b)

FIGURE 1: Changes in mass and heat flow of iron ore samples Ug3 and Ug2 during heating from the ambient temperature and up to $1400^{\circ} \mathrm{C}$.

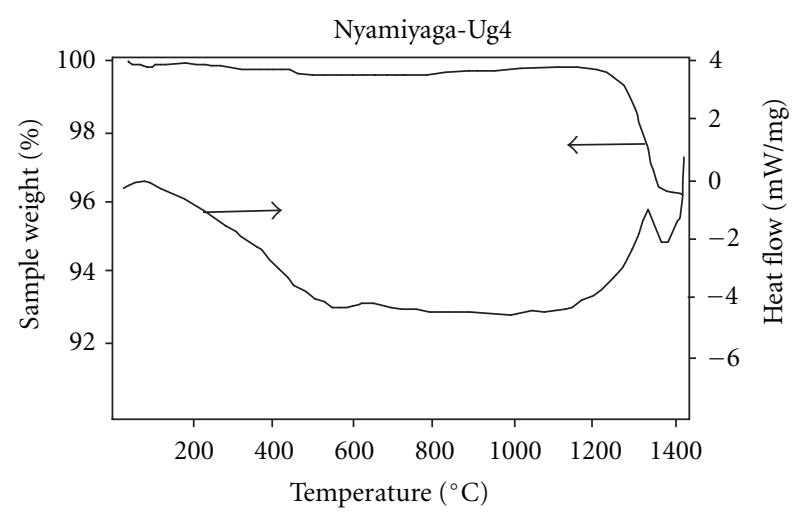

(a)

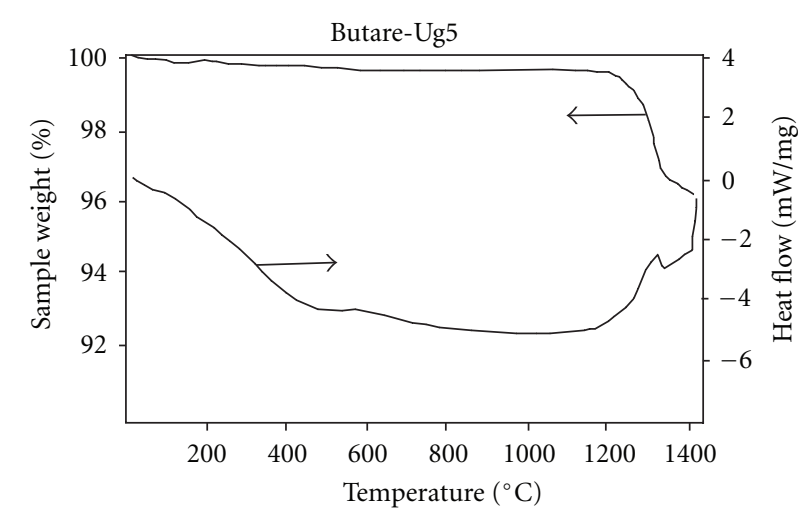

(b)

FIgURE 2: Mass and heat flow changes as a function of temperature for samples Ug4 and Ug5.

bonded water (goethite and $\mathrm{Fe}_{2} \mathrm{O}_{3}$ hydrate). When this is driven off it leaves only $\alpha$-hematite phase, Figure 4 . This statement is confirmed by the highest value of weight loss $(1.57 \%)$ in the Ug6 sample below $800^{\circ} \mathrm{C}$ compared to all other studied samples.

An additional endothermal effect below $800^{\circ} \mathrm{C}$ also depends directly on the weight loss of the sample, due to the removal of physically present and structurally bonded water. It can be seen in Figures 1-3 that the slope of the DTA curve on the thermogram, which defines the additional endothermal effect, increases with increased values of the mass change. This is observed at temperatures below $800^{\circ} \mathrm{C}$ among all the samples. The small weight loss in Figures 1-3 recorded up to $200^{\circ} \mathrm{C}$ is due to a loss of the physically combined water from the ore as observed in Figure 4. Between $200^{\circ} \mathrm{C}$ and $450^{\circ} \mathrm{C}$, a number of reactions take place such as the decomposition of hydrates (1) and dehydroxylation reaction of goethite to hematite $(2)[15,16]$ :

$$
\begin{gathered}
2 \mathrm{OH}^{-} \stackrel{\text { heat }}{\longrightarrow} \mathrm{O}^{2-}+\mathrm{H}_{2} \mathrm{O} \\
2 \alpha-\mathrm{FeOOH} \stackrel{\text { heat }}{\longrightarrow} \alpha-\mathrm{Fe}_{2} \mathrm{O}_{3}+\mathrm{H}_{2} \mathrm{O} .
\end{gathered}
$$

To estimate the energy requirements in heating up each sample up to $1100^{\circ} \mathrm{C}$, calculations for the endothermal effect were made. This was accomplished by calculating the slope of the DTA curve (for the downward trend part). The results are presented in Table 2. It is interesting to note that the Ug6 and Ug5 iron ore samples, which have a broader size range of irregular grains $(\sim 30$ to $>500 \mu \mathrm{m})$ as well as the biggest contaminations [6], have the largest values of the endothermal effect (5.57 and $4.98 \mathrm{~mW} / \mathrm{mg}$, resp.). Therefore, it may be safely suggested that the energy consumption for heating of Muko iron ores up to $1100^{\circ} \mathrm{C}$ increases in the samples in the following order $\mathrm{Ug} 1<(\mathrm{Ug} 2, \mathrm{Ug} 3, \mathrm{Ug} 4)<\mathrm{Ug} 5$ $<$ Ug6.

It was also noted that all samples exhibit an exothermic peak in the temperature range $1267^{\circ} \mathrm{C}$ to $1361^{\circ} \mathrm{C}$. It should be noted that the peak area of released energy (154-188 $\mathrm{J} / \mathrm{g}$ ) is almost the same for all samples. This is also true with respect to the corresponding weight loss above $1100^{\circ} \mathrm{C}$ (3.22-3.50 wt \%). This implies that the phase transformation occurring in this temperature range is entirely due to the decomposition of hematite to magnetite, according to (3), as observed in Figure 4:

$$
3 \mathrm{Fe}_{2} \mathrm{O}_{3} \stackrel{\text { heat }}{\longrightarrow} 2 \mathrm{Fe}_{3} \mathrm{O}_{4}+0.5 \mathrm{O}_{2}(\mathrm{~g}) \text {. }
$$


TABLE 2: Mass change and peaks of phase transformations during the thermoanalysis of Muko iron ores*.

\begin{tabular}{|c|c|c|c|c|c|c|c|}
\hline Iron ore & $\begin{array}{l}\text { Mass change below } \\
800^{\circ} \mathrm{C}(\mathrm{wt} \%)\end{array}$ & $\begin{array}{c}\text { Mass change above } \\
1100^{\circ} \mathrm{C}(\mathrm{wt} \%)\end{array}$ & $T_{(\text {Peakl) }}\left({ }^{\circ} \mathrm{C}\right)$ & $\begin{array}{c}\text { Absorption energy } \\
\text { of Peak } 1(\mathrm{~J} / \mathrm{g})\end{array}$ & $\begin{array}{c}\text { Endothermal effect } \\
(\mathrm{mW} / \mathrm{mg})\end{array}$ & $\begin{array}{c}T_{(\text {Peak2) }} \\
\left({ }^{\circ} \mathrm{C}\right)\end{array}$ & $\begin{array}{l}\text { Release energy } \\
\text { of Peak } 2(\mathrm{~J} / \mathrm{g})\end{array}$ \\
\hline $\mathrm{Ug} 1$ & 0.13 & 3.50 & 533 & 454 & 3.27 & 1329 & 154 \\
\hline Ug2 & 0.46 & 3.22 & 538 & 929 & 3.95 & 1328 & 188 \\
\hline Ug3 & 0.50 & 3.34 & 536 & 1076 & 4.09 & 1326 & 165 \\
\hline $\mathrm{Ug} 4$ & 0.31 & 3.28 & 506 & 745 & 3.95 & 1333 & 175 \\
\hline Ug5 & 0.44 & 3.46 & 467 & 505 & 4.98 & 1329 & 180 \\
\hline Ug6 & 1.57 & 3.45 & - & - & 5.57 & 1324 & 167 \\
\hline
\end{tabular}

${ }^{*}$ Peak 1: endothermal peak, Peak 2: exothermal peak.

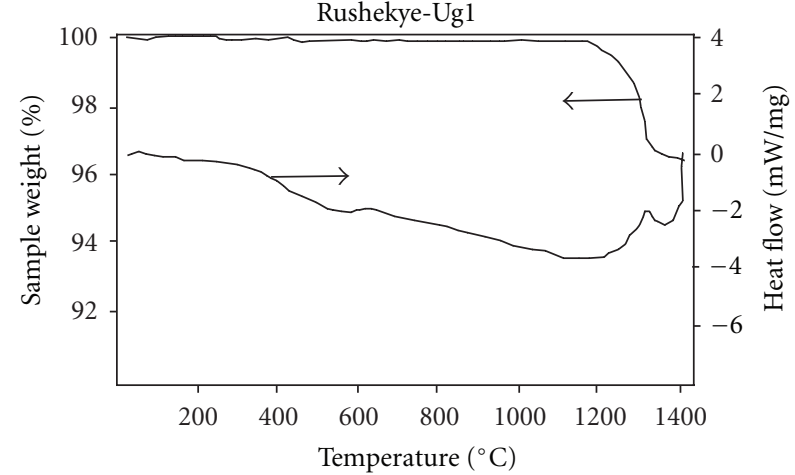

(a)

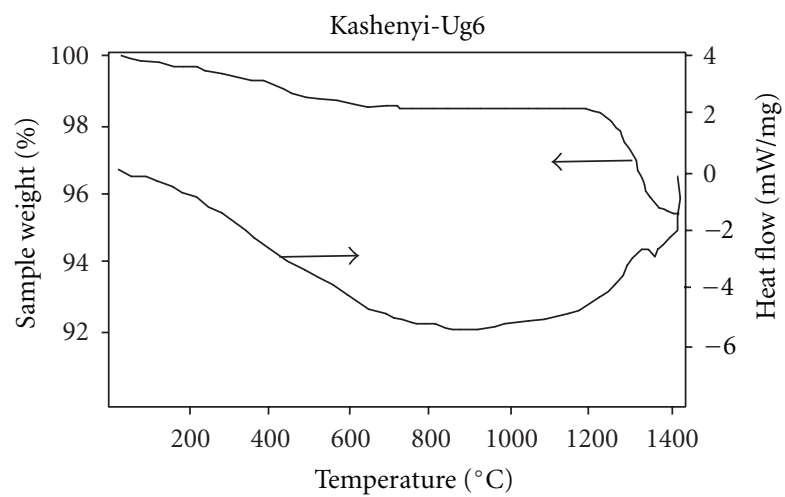

(b)

FIgURE 3: Mass and heat flow changes as a function of temperature for samples Ug1 and Ug6.

3.2.2. Reducibility. Reducibility parameters illustrate the possibility for removal of oxygen combined with Fe from the iron ore. A high reducibility is desirable, since it decreases the amount of reducing gas required to realise a given amount of metal from a given amount of ore. The rate at which the iron oxide can be reduced to metallic iron is the primary determinant of the rate of production in any reduction process [8].

A reducibility test was performed on sample Ug6 from the Kashenyi deposit, which has the lowest quality level in comparison to the other samples. Explicitly, this sample has a lower $\mathrm{Fe}$ content $(60.6 \%)$ and higher contents of $\mathrm{SiO}_{2}(5.1 \%)$ and $\mathrm{Al}_{2} \mathrm{O}_{3}(6.0 \%)$. Moreover, it also has a higher level of physically present and structurally bonded water, as observed from the thermoanalysis. The results of reducibility test for Ug6 sample are shown in Figure 5.

It can be observed that the mass change of the Ug6 sample during heating up to $450^{\circ} \mathrm{C}$ is $1.52 \mathrm{wt} \%$ (points A to $\mathrm{B}$ on Figure 5), which corresponds well to the weight loss value of $1.57 \mathrm{wt} \%$ obtained from the thermoanalysis. As was explained in Section 3.2.1, this mass change of sample Ug6 is due to the loss of physically and chemically combined water, as observed in Figure 5.

The reducing gas $\left(40 \% \mathrm{CO}+60 \% \mathrm{~N}_{2}\right)$ was introduced into the system at $950^{\circ} \mathrm{C}$. It is realised that there was a steady increase in the weight loss from this point, $2.63 \mathrm{wt} \%$ (C to D), $4.04 \mathrm{wt} \%$ (D to E), and $17.23 \mathrm{wt} \%$ (E to F). The overall weight loss at $950^{\circ} \mathrm{C}$ is $23.88 \mathrm{wt} \%$ (C to F). This weight loss is due to the reduction of hematite to its lower oxides as shown in (4)-(6):

$$
\begin{gathered}
3 \mathrm{Fe}_{2} \mathrm{O}_{3}+\mathrm{CO}=2 \mathrm{Fe}_{3} \mathrm{O}_{4}+\mathrm{CO}_{2} \\
\mathrm{Fe}_{3} \mathrm{O}_{4}+\mathrm{CO}=3 \mathrm{FeO}+\mathrm{CO}_{2} \\
\mathrm{FeO}+\mathrm{CO}=\mathrm{Fe}+\mathrm{CO}_{2},
\end{gathered}
$$

where the overall reduction reaction equation can be written as follows:

$$
\mathrm{Fe}_{2} \mathrm{O}_{3}+3 \mathrm{CO}=2 \mathrm{Fe}+3 \mathrm{CO}_{2} .
$$

The reducibility index (RI), which indicates the reduction rate and reduction degree, indicating the extent of reduction, were defined and calculated by using (8) and (9), respectively [8],

$$
\mathrm{RI}=\frac{d R}{d t}(40 \% \text { reduction })=\frac{33.6}{t_{60}-t_{30}},
$$

where $t_{30}$ and $t_{60}$ are the times to attain a $30 \%$ and a $60 \%$ degree of reduction, respectively ( $\mathrm{min})$,

$$
\mathrm{RD}=\left[\frac{0.111 \cdot W_{1}}{0.430 \cdot W_{2}}+\frac{\left(m_{1}-m_{t}\right)}{m_{0} \cdot 0.430 \cdot W_{2}} \cdot 100\right] \cdot 100,
$$

where $m_{0}, m_{1}$, and $m_{t}$ are the masses of the test sample before the reduction test, immediately before starting the reaction 


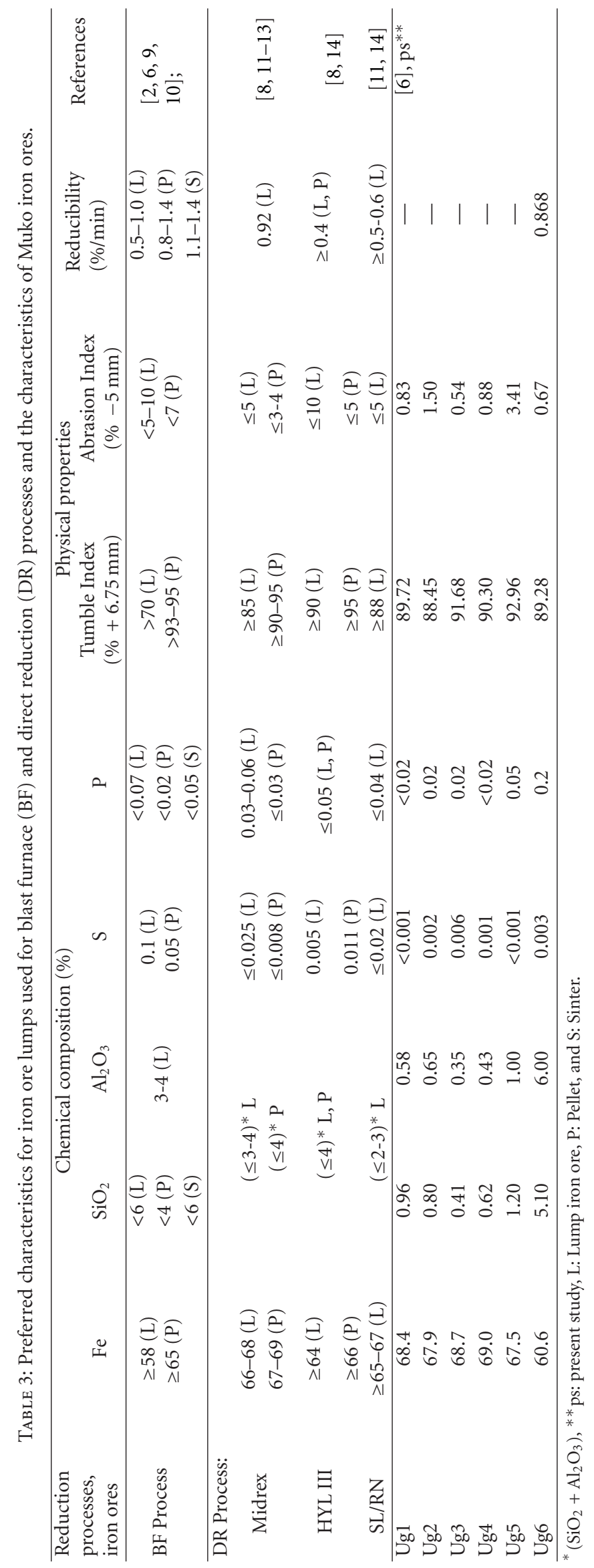




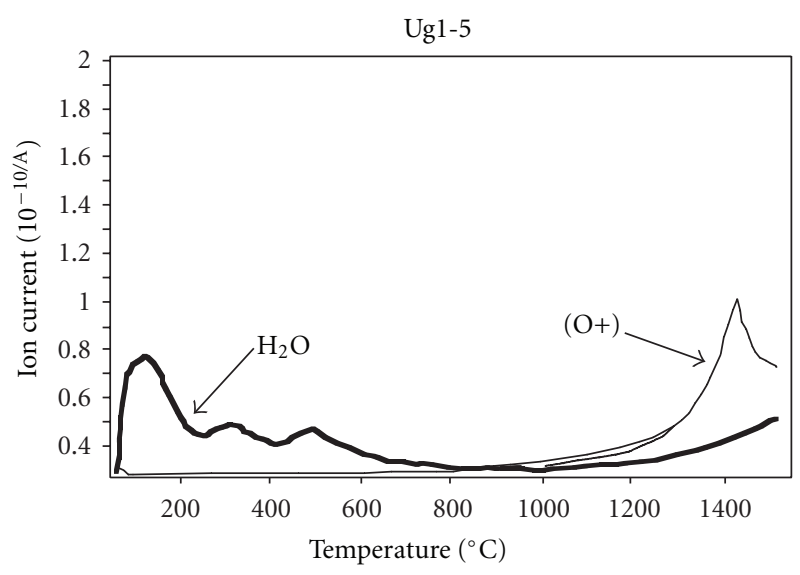

(a)

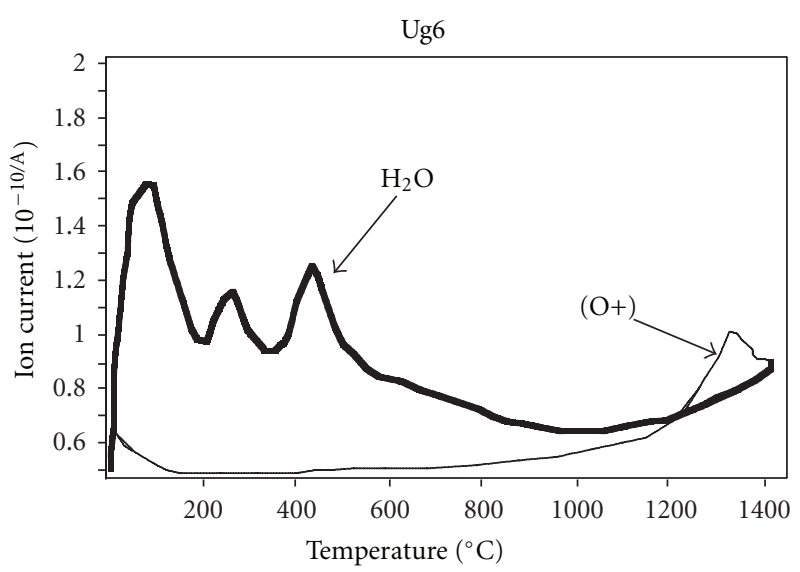

(b)

FIgURE 4: Evolution of volatiles during heating of Muko iron ore samples.

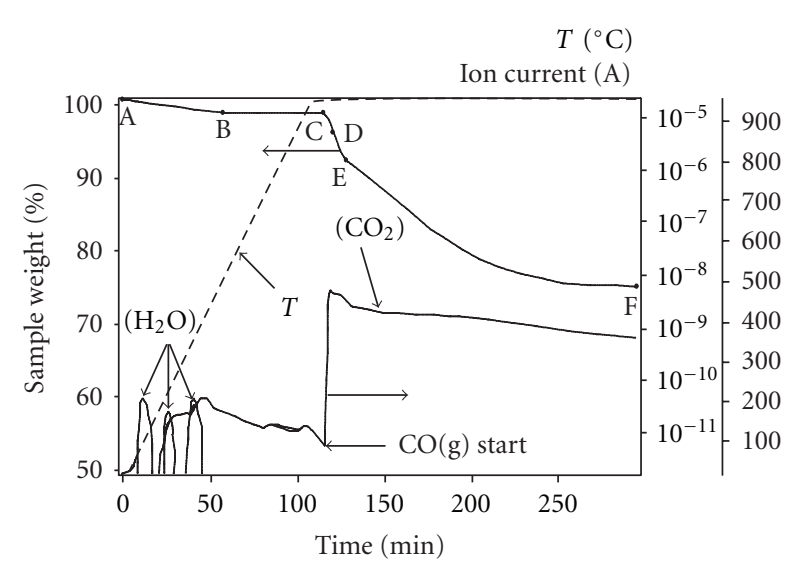

FIGURE 5: Graph showing the reduction of Kashenyi iron ore sample, monitored as the change in sample weight with time.

and after a reduction time $t$, respectively. Furthermore, the parameter $W_{2}$ is the total iron content of the test sample prior to the test $(60.6 \% \mathrm{Fe})$. Additionally, $W_{1}$ is the content of $\mathrm{Fe}^{2+}$ oxide in the sample prior to the reduction test (mass $\%$ ), which is calculated from the $\mathrm{Fe}^{2+}$ content by multiplying it by a factor of 1.286 [17].

In this study, the reducibility index, RI, for the Ug6 sample was calculated as $0.868 \% / \mathrm{min}$ and the reduction degree, $\mathrm{RD}$, as $91.28 \%$. As sample Ug6 has the lowest content among Muko iron ore samples, it is safe to assume that the reducibility parameters of samples Ug1-5 will be higher.

Usually the reduction rate of iron ores should be $0.5-$ $1.0 \% / \mathrm{min}$ for the blast furnace process [10] and at least $0.4 \%$ for the direct reduction in the HYL III process (gas as reductant) [8]. Furthermore for the direct reduction in the rotary kiln furnace, which is one of the methods using coal as a reductant, the rate should at least be $0.5-0.6 \% / \mathrm{min}$ [11]. In practice, the values of the reduction rate for iron ores vary in the range from 0.4 to $0.9 \% / \mathrm{min}$ [15]. It can be seen that the RI value for the Ug6 sample is significantly higher than the acceptable value for direct reduction. In addition, it
(1)

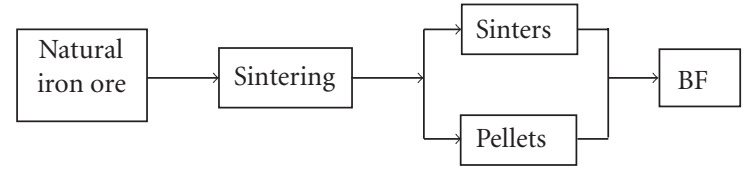

(2)

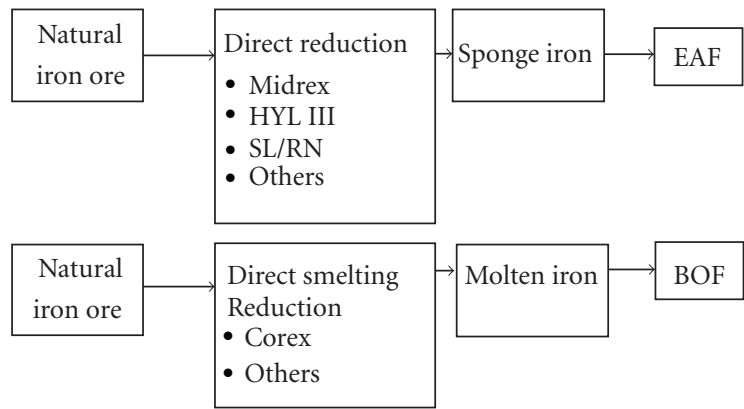

(4)

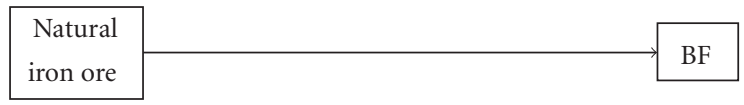

FIGURE 6: Schematic illustration of the main routes of iron production.

lies within the appropriate interval of the reduction rate for the blast furnace process. Thus, it may be concluded that all studied iron ores from the different Muko deposits can easily be reduced to iron within the required tolerances in the blast furnace as well as direct reduction furnaces.

\section{Possible Prospects of Using Muko Iron Ore for Iron Production}

Natural iron ores are used for iron making through the blast furnace $(\mathrm{BF})$ process and direct reduction (DR) or direct smelting reduction (DSR) processes. The major routes for application of natural iron ores are schematically illustrated in Figure 6. Route 1, by which sinters and pellets produced by sintering of crushed and enriched natural iron ores for use in $\mathrm{BF}$ and electric arc furnace (EAF), is the routine method. 
Most of the iron ores, irrespective of quality, can be used in this route after crushing, grinding, and enrichment.

In the DR process (Route 2), only natural ores with high physical and metallurgical properties are applied. Among the numerous processes for direct reduction of iron ore, the Midrex and HYL III (by means of gas) and the SL/RN (rotary Kiln; by means of coal reduction) have had the most successful industrial implementation $[13,18,19]$. The Midrex process contributes to the biggest share of the directly reduced iron (DRI) produced, which corresponds to about $60 \%$ of the world production $[12,13,20]$.

Today, the DSR process (Route 3 ) which produces molten iron has not made a pronounced contribution to iron production compared to the previous two routes. Therefore, this method was not analysed and evaluated in this study.

Natural ore can also be charged directly to the BF as part of the furnace feed (15-20\%) [4], (Route 4). Only highgrade iron ores with high levels of physical and metallurgical characteristics can be efficiently used directly in the BF process.

Table 3 shows some of the characteristic requirements on natural iron ore lump, pellets and sinters, to serve as a feed material to the main iron production processes. The characteristics of Muko iron ores from the different deposits are also given in this table. It follows from Table 3 that the iron ores Ug1-Ug5 meet the chemical requirements as natural materials for the BF (Routes 1 and 4) and DR furnaces (Route 2). The content of $\mathrm{Fe}, \mathrm{SiO}_{2}$, and $\mathrm{Al}_{2} \mathrm{O}_{3}$ in the Ug6 sample falls short of the given requirements for DR (Route 2) and for direct charging in the $\mathrm{BF}$ (Route 4). However, the other characteristics of this sample (such as physical properties and reducibility) are within the acceptable limits. Therefore, the natural iron ore from the Kashenyi deposit (Ug6) can also be used as a natural material for production of pellets and sinters (Route 1) or as some part of charge with other higher-quality ores (Ug1-Ug5) for DR processes (Route 2).

Figure 7 shows the comparison of the physical properties of natural iron ore from Muko deposits, with the physical requirements for lump ores used for $\mathrm{BF}$ and $\mathrm{DR}$ processes. It can be seen that the physical properties of natural iron ores from all Muko deposits are within the acceptable limits for $\mathrm{BF}$ processes as well as the different DR methods (Midrex and SL/RN_all samples, HYL III-Ug3-Ug5).

According to the obtained results in this study, the possible prospects of using natural iron ores from the different deposits of Muko for iron production can be summarised as follows.

BF process (Route 1): all samples.

DRI process (Route 2):

Midrex: all samples, SL/RN: all samples, HYL III: Ug3 Ug5 samples.

BF process (Route 4): Ug1 Ug5 samples.

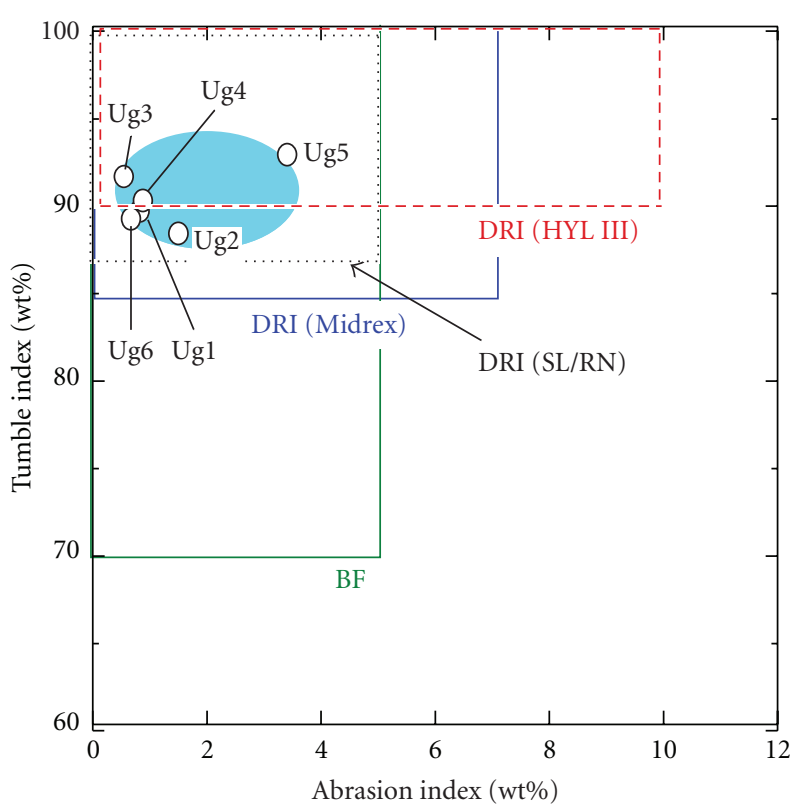

Figure 7: Comparison of physical properties of natural iron ores from the Muko deposits to the physical requirements for lump ores used for blast furnace (BF) and direct reduction (Midrex, HYL III and SL/RN) processes.

\section{Conclusion}

Based on the test of physical (tumbler, abrasion, and shatter indexes) and metallurgical (characteristics of thermoanalysis and reducibility) properties for natural iron ores from the different deposits of Muko (Uganda), the following conclusions can be made.

(1) The natural iron ores from all Muko deposits have high physical property values (Tumbler Index is $85 \sim$ $93 \mathrm{wt} \%$, Abrasion Index is $0.5 \sim 3.4 \mathrm{wt} \%$ and Shatter Index is $0.5 \sim 2.0 \mathrm{wt} \%$ ). Therefore, these ores can be easily handled, loaded, transported and charged into a reduction furnace without disintegrating into small particles in the form of dust.

(2) The physical properties of Muko iron ores meet the feed natural material requirements for the blast furnace and different methods for direct reduction of iron (Midrex, HYL III, and SL/RN). Only samples Ug1, -2 , and -6 fall short of meeting the HYL III requirements. This is due to their TI values falling short of the $90 \mathrm{wt} \%$ requirement for this process.

(3) Thermoanalysis shows that all Muko iron ores exhibit endothermal and exothermal effects below $700^{\circ} \mathrm{C}$ and above $1100^{\circ} \mathrm{C}$, respectively. The endothermal peaks observed in the Ug1-Ug5 samples in the temperature range $365-632^{\circ} \mathrm{C}$ are due to the transformation of $\gamma$ hematite (maghemite) to $\alpha$-hematite. The absence of the $\gamma$ - $\alpha$-hematite phase transition in the Ug6 sample is due to the larger content of chemically bonded water (goethite and $\mathrm{Fe}_{2} \mathrm{O}_{3}$ hydrate), which when dissociated leaves only $\alpha$-hematite phase. The energy 
consumption during the heating of Muko iron ores up to $1100^{\circ} \mathrm{C}$ correlates also well to the removal of physically present and structurally bonded water. This removal increases in the following sample order: $\mathrm{Ug} 1<(\mathrm{Ug} 2, \mathrm{Ug} 3, \mathrm{Ug} 4)<\mathrm{Ug} 5<\mathrm{Ug} 6$. In addition, the exothermic effect in the temperature range $1267^{\circ} \mathrm{C}$ to $1361^{\circ} \mathrm{C}$, which correlates with the decomposition of hematite to magnetite, is almost the same (154$188 \mathrm{~J} / \mathrm{g}$ ) for all Muko ore samples.

(4) The obtained value of reducibility index of $0.868 \% /$ min for the Ug6 sample is acceptable for DRI and BF processes.

Based on the analysis of chemical composition and physical and metallurgical properties, it may be safely suggested that the natural iron ores from Muko deposits can be efficiently used as natural materials for production of pellets and sinters. Moreover, they serve well for the direct reduction process and for partial charging into the blast furnace.

\section{References}

[1] World Steel in Figures, 2011, World Steel Association, Brussels , Belgium, 2011.

[2] "Evaluation of iron ore pellets and sinters for BF and DR use," The Southern African Institute of Mining and Metallurgy, 2009, http://www.saimm.co.za/events/0809pelsint/downloads/Mashao.pdf.

[3] M. Kumar, S. Jena, and S. K. Patel, "Characterization of properties and reduction behavior of iron ores for application in sponge ironmaking," Mineral Processing and Extractive Metallurgy Review, vol. 29, no. 2, pp. 118-129, 2008.

[4] S. L. Wu, H. F. Xu, and Y. Q. Tian, "Evaluation of lump ores for use in modern blast furnaces as part of mixed burden practice," Ironmaking and Steelmaking, vol. 36, no. 1, pp. 1923, 2009.

[5] T. Sharma, R. C. Gupta, and B. Prakash, "Effect of gangue content on the swelling behaviour of iron ore pellets," Minerals Engineering, vol. 3, no. 5, pp. 509-516, 1990.

[6] A. J. B. Muwanguzi, A. V. Karasev, J. K. Byaruhanga, and P. G. Jönsson, Characterisation of the Chemical Composition and Microstructure of Natural Iron Ore from Muko Deposits in Uganda, KTH Royal Institute of Technology, 2010.

[7] Iron Ores-Determination of Tumble Strength, International Standard, ISO 3271:1995(E), Geneva, 3rd edition, 1995, Case Postal 56, CH-1211.

[8] A. Chatterjee, Beyond the Blast Furnace, CRC Press, Boca Raton, Fla, USA, 1994.

[9] O. Lingiard, O. Burrai, C. Partemio, F. Giandoménico, P. Etchevarne, and J. M. Gonzalez, "High productivity and coke rate reduction at Siderar blast furnace \#2," in Proceedings of the 1st International Meeting on Ironmaking, Belo Horizonte, Brazil, 2001.

[10] A. K. Biswas, Principles of Blast Furnace Iron Making, SBA Publications, Calcutta, India, 2005.

[11] “Sponge Iron Report,” 2010, Sponge Iron Manufacturer's Association, http://www.scribd.com/doc/7278475/Sponge-IronReport.

[12] “The World of Direct Reduction," Midrex Technologies, 2000, http://www.midrex.com/.
[13] "World Direct Reduction Statistics," Midrex, 2008, http://www .midrex.com/uploads/documents/MIDREXStatsBook2008 .pdf.

[14] “Raw Materials," HYL, 2010, http://www.energiron.com/ tour/HYL\%20DR-Minimill\%20QTVR\%20tour/files/support -docs/overview/rawmaterials.pdf.

[15] A. Cores, A. Babich, M. Muñiz, A. Isidro, S. Ferreira, and R. Martín, "Iron ores, fluxes and tuyere injected coals used in the blast furnace," Ironmaking and Steelmaking, vol. 34, no. 3, pp. 231-240, 2007.

[16] R. M. Cornell and U. Scwertmann, The Iron Oxides, Structure, Properties, Reactions, Occurrences and Use, Wiley-VCH, Weinheim, Germany, 2006.

[17] Iron Ores-Determination of Reducibility, International Standard, ISO 4695:1995, Switzerland, 2nd edition, 1995, Case Postale 56, CH-1211.

[18] T. Zervas, J. T. Mcmullan, and B. C. Williams, "Developments in iron and steel making," International Journal of Energy Research, vol. 20, no. 1, pp. 69-91, 1996.

[19] M. Cojić and S. Kožuh, "Development of direct reduction processes and smelting reduction processes for the steel production," Kemija u Industriji, vol. 55, no. 1, pp. 1-10, 2006.

[20] J. Kempken, G. Kleinschmidt, K. Schmale, U. Thiedemann, H. P. Gaines, and J. T. Kopfle, "Short route-long-term success: integrated mini-mill solutions by midrex and SMS demag," Archives of Metallurgy and Materials, vol. 53, no. 2, pp. 331336, 2008. 

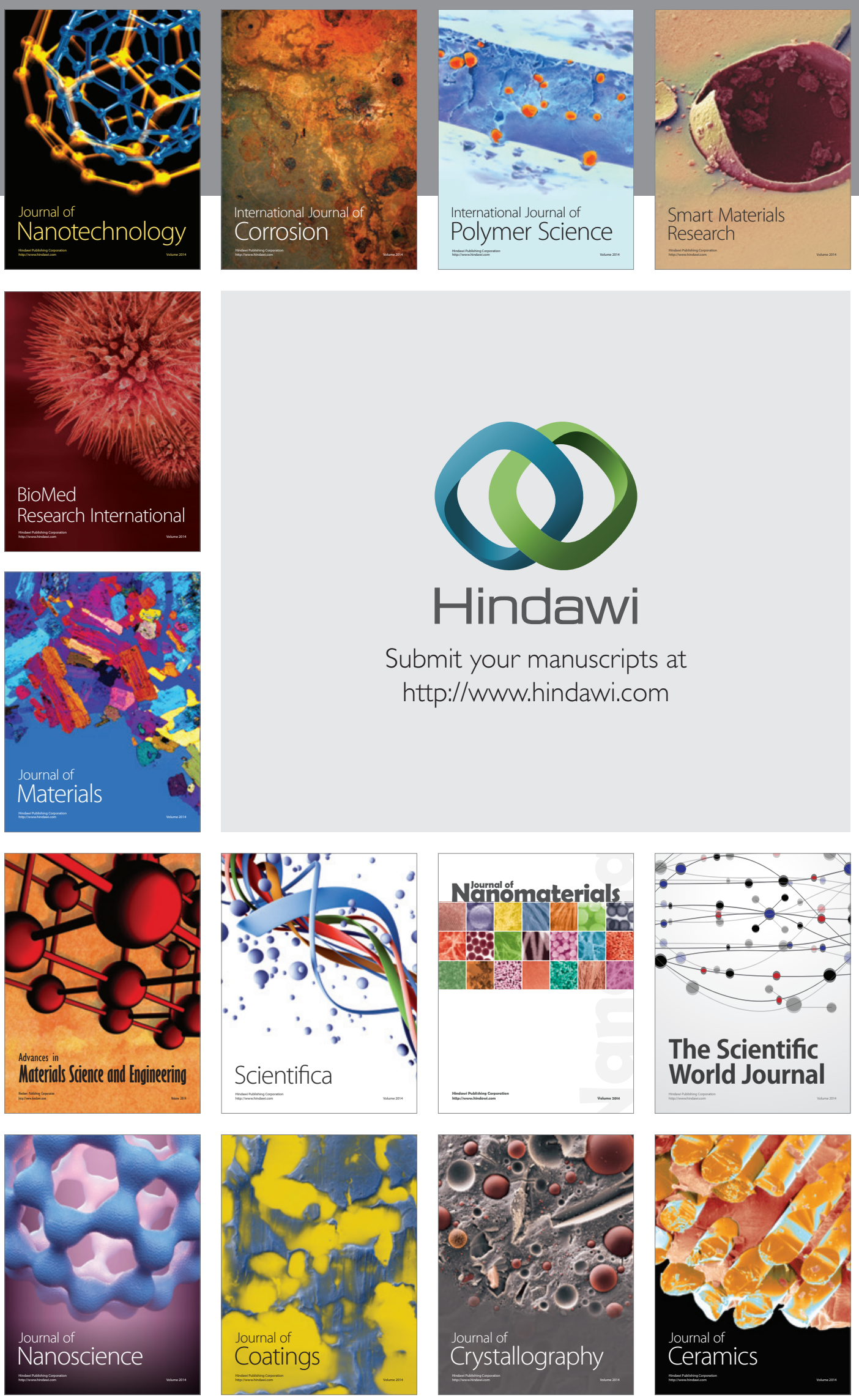

The Scientific World Journal

Submit your manuscripts at

http://www.hindawi.com

\section{World Journal}

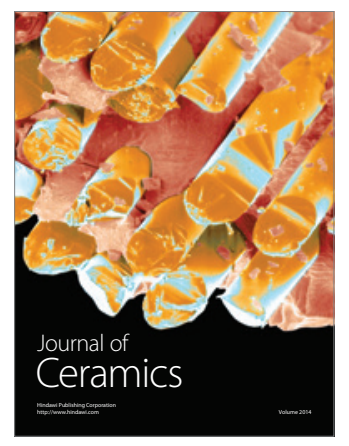

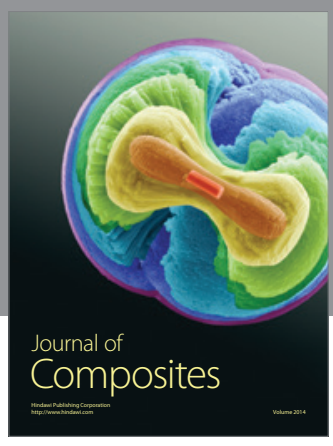
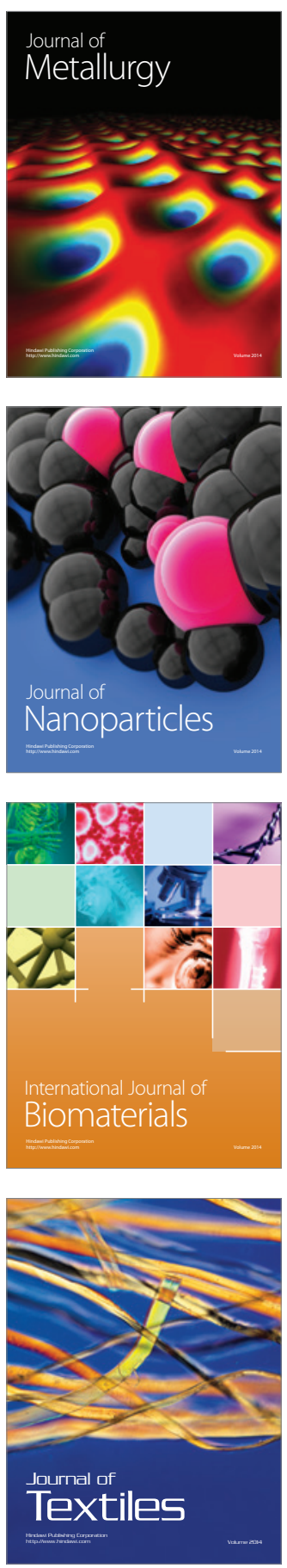